\title{
Histone Demethylase JMJD2A Inhibition Attenuates Neointimal Hyperplasia in the Carotid Arteries of Balloon-Injured Diabetic Rats via Transcriptional Silencing: Inflammatory Gene Expression in Vascular Smooth Muscle Cells
}

\author{
Hu Qja Zhang Jing ${ }^{b}$ Wu Xiaolinc Xu Changwu ${ }^{a}$ Hu Xiaoronga Yang Jian ${ }^{b}$ \\ Chen Jing ${ }^{\text {a Jiang Hong }}{ }^{\text {a }}$ \\ aDepartment of Cardiology, Renmin Hospital of Wuhan University, Cardiovascular Research Institute of \\ Wuhan University, Wuhan, bDepartment of Cardiology, The First College of Clinical Medical Sciences, \\ China Three Gorges University, Yichang, Hubei, 'Department of Cardiology, Xiangyang Central Hospital, \\ Affiliated Hospital of Hubei University of Arts and Science, Xiangyang, Hubei, China
}

\section{Key Words}

JMJD2A • Restenosis • Neointimal hyperplasia • Diabetes • Inflammation • Vascular smooth muscle cell

\begin{abstract}
Background/Aims: Diabetic patients suffer from severe neointimal hyperplasia following angioplasty. The epigenetic abnormalities are increasingly considered to be relevant to the pathogenesis of diabetic cardiovascular complications. But the epigenetic mechanisms linking diabetes and coronary restenosis have not been fully elucidated. In this study, we explored the protective effect and underlying mechanisms of demethylases JMJD2A inhibition in ballooninjury induced neointimal formation in diabetic rats. Methods: JMJD2A inhibition was achieved by the chemical inhibitor 2,4-pyridinedicarboxylic acid (2,4-PDCA) and small interfering RNA (siRNA). In vitro, we investigated the proliferation, migration and inflammation of rat vascular smooth muscle cells (VSMCs) in response to high glucose (HG). In vivo, diabetic rats induced using high-fat diet and low-dose streptozotocin $(35 \mathrm{mg} / \mathrm{kg})$ underwent carotid artery balloon injury. Morphometric analysis was performed using hematein eosin and immumohistochemical staining. Chromatin Immunoprecipitation (ChIP) was conducted to detect modification of H3K9me3 at inflammatory genes promoters. Results: The global JMJD2A was increased in HG-stimulated VSMCs and balloon-injured arteries of diabetic rats, accompanied by decreased H3K9me3. The inhibition of JMJD2A suppressed VSMCs proliferation, migration and inflammation induced by high glucose $(\mathrm{HG})$ in vitro. And JMJDA2A inhibition attenuated
\end{abstract}

Jiang Hong and Chen Jing

KARGER 125
Department of Cardiology, Renmin Hospital of Wuhan University, Cardiovascular Research Institute of Wuhan University, 238 Jiefang Road, Wuhan 430060, (China) Fax +86 027 88083385, E-mail pyh_hongj@163.com 


\section{Cellular Physiology Cell Physiol Biochem 2015;37:719-734

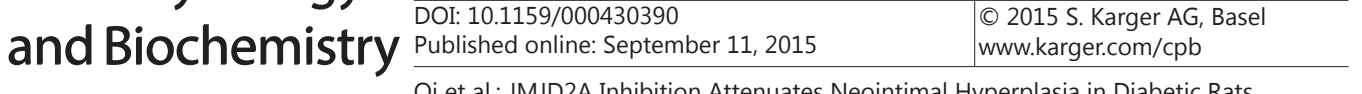

neointimal formation in balloon-injured diabetic rats. The underlying mechanisms were relevant to the restoration of $\mathrm{H} 3 \mathrm{~K} 9 \mathrm{me} 3$ levels at the promoters of MCP-1 and IL- 6 , and then the suppressed expression of MCP-1 and IL-6. Conclusion: The JMJD2A inhibition significantly attenuated neointimal formation in balloon injured diabetic rats via the suppression of VSMCs proliferation, migration, and inflammation by restoring $\mathrm{H} 3 \mathrm{~K} 9 \mathrm{me} 3$.

Copyright (C) 2015 S. Karger AG, Basel

\section{Introduction}

Diabetes mellitus (DM) is a significant risk factor for coronary artery disease (CAD) $[1,2]$. Patients with both CAD and diabetes suffer from increased cross-sectional luminal narrowing and heavy plaque burdens [3, 4]. Compared with nondiabetic patients, patients with diabetes often exhibit severe neointimal hyperplasia following coronary interventions [5]. Even the implantation of drug-eluting stents is unsatisfying in remitting the restenosis and unfavorable clinical outcomes [6, 7]. Recently, several large clinical trials (e.g. ADVANCE, ACCORD and VADT) demonstrate that intensive glycemic control is not fully efficacious in preventing diabetic complications [8-10]. This ineffectiveness is associated with a potential mechanism defined as 'metabolic memory', which refers to individuals continue to exhibit low-grade inflammation and develop vascular complications even under intensive glycemic control [11]. Restenosis is a complex pathological process characterized by inflammation, thrombosis, cellular proliferation, and extracellular matrix production in response to mechanical injury [12]. The inflammation plays an important role in this process, provoking vascular smooth muscle cells (VSMCs) to migrate to the intima and proliferate and synthesize the extracellular matrix, thereby resulting in neointimal formation [13].

Increasing evidence indicates that epigenetic abnormalities are implicated in metabolic memory and diabetic vascular complications [14]. Histone methylation, a modification of the $\mathrm{N}$-terminal trials of core histones, occurs on either lysine or arginine residue. This epigenetic modification participates in a variety of biological processes, including heterochromatin formation, X-chromosome inactivation and transcriptional regulation $[15,16]$. It is a dynamic process in which histone methyltransferases and demethylases catalyze both the addition and removal of methyl groups, thereby resulting in mono- (me), di- (me2), or tri- (me3) methylation $[17,18]$. One of the extensive studied histone methylation that is relevant to inflammatory gene expression occurs on histone H3 lysine 9 (H3K9) tail. The decreased trimethylation of $\mathrm{H} 3 \mathrm{~K} 9$ (H3K9me3) at the promoters of inflammatory genes is associated with increased MCP-1 and IL-6 expression in diabetic VSMCs [19].

JMJD2A, a JmjC domain-containing histone demethylase, is capable of removing the methyl group from $\mathrm{H} 3 \mathrm{~K} 9 m e 3$ in the presence of oxygen using $\mathrm{Fe}^{2+}$ and 2-oxoglutarate (2-OG) as cofactors [20]. Trough catalyzing H3K9me3 demethylation, JMJD2A promotes an open chromatin state and contributes to the transcriptional activation [21]. It transcriptionally regulates cancer-related genes including cell cycle, proliferation and inflammation. However, the potential function of JMJD2A in diabetic vascular complications has not been fully elucidated. In this study, we explored the possible protective effects and underlying mechanisms of JMJD2A inhibition in VSMC migration, proliferation and inflammation in vitro in response to diabetic stimuli as well as neointima formation in vivo following arterial injury in diabetic rats.

\section{Materials and Methods}

Animals and ethics statement

All animals used in our study were purchased from the Animal Center of Renmin Hospital of Wuhan University. The experimental procedures and animal care procedures were conducted in accordance with the Institutional Animal Care and Use Committee of Wuhan University. All animals were housed under temperature-controlled conditions $\left(21^{\circ} \mathrm{C}-26^{\circ} \mathrm{C}\right), 40 \%-70 \%$ humidity, and $15-20$ Lux lighting. 


\section{Cellular Physiology Cell Physiol Biochem 2015;37:719-734 \\ \begin{tabular}{c|c|c|}
\cline { 2 - 2 } DOI: 10.1159/000430390 & O 2015 S. Karger AG, Basel
\end{tabular} \\ and Biochemistry Published online: September 11, $2015 \quad$ www.karger.com/cpb \\ Qi et al.: JMJD2A Inhibition Attenuates Neointimal Hyperplasia in Diabetic Rats}

\section{2,4-pyridinedicarboxylic acid (2,4-PDCA) treatment in vitro and in vivo}

2,4-PDCA (Sigma) was dissolved in sodium bicarbonate to form a $100 \mathrm{mM}$ stock solution or a $15 \mathrm{mg} /$ $\mathrm{ml}$ salt solution for in vitro and in vivo study, respectively. The $\mathrm{pH}$ was adjusted to $7.4 \mathrm{using} 1 \mathrm{~mol} / \mathrm{L}$ Tris-HCL (pH 8.8). In vitro study, cells were pretreated with 2,4-PDCA in various concentrations $(0.125,0.25,0.5,1.0$ $\mathrm{mM})$. In vivo study, the rats were administrated daily intraperitoneal injections of 2, 4-PDCA (7.5, 15, or 30 $\mathrm{mg} / \mathrm{kg} / \mathrm{d}$ ) or normal saline two days after surgery until the rats were euthanized.

\section{Small interfering RNA transfection in vitro and in vivo}

Small interfering RNA (siRNA) specific to rat JMJD2A was purchased from Invitrogen and the sequence was listed as follow: 5'-GAGCAGAUGUGAAUGGUACUCUCUA-3' (Invitrogen). For the transfection in vitro, VSMCs seeded in 6-well plates at 70\% confluence were transfected with the siRNA-JMJD2A at the final concentrations of 5, 10, and $20 \mathrm{nM}$ using Lipofectamine 2000 according to the manufacturer's instructions (Invitrogen). For the transfection in vivo, $15 \mu \mathrm{g}$ siRNA-JMJD2A was dissolved in $100 \mu \mathrm{L}$ of $30 \%$ pluronic gel solution (Sigma) and perivascularly delivered to the rat carotid arteries immediately after injury as described previously [22]. Scrambled siRNA was used as negative control at the same concentration.

\section{Cell culture and high glucose, fatty acid and insulin treatment}

Rat VSMCs were isolated from the thoracic aortas of male SD rats (150-180 g) and cultured in Dulbecco's modified serum (DMEM, Hyclone) containing $5.5 \mathrm{mM}$ glucose (NG), 10\% fetal bovine serum (FBS, Hyclone) and $1 \%$ penicillin/streptomycin (PS, Hyclone), at $37^{\circ} \mathrm{C}$ in an atmosphere of $5 \% \mathrm{CO}_{2}$ [23]. VSMCs at the $3^{\text {rd }}$ to the $5^{\text {th }}$ passage were used for all experiments. For high glucose, fatty acid and insulin stimulation experiments, serum-starved VSMCs were stimulated with fresh medium containing $25 \mathrm{mM}$ glucose (HG), $400 \mu \mathrm{M}$ palmitate (Sigma) and $100 \mathrm{nM}$ insulin (Novo Nordisk Pharmaceutical Industries) [24, 25].

\section{Cell proliferation}

Cell proliferation was assessed using a cell counting kit-8 assay (CCK-8, Dojindo Laboratories) and bromodeoxyuridine (BrdU, Roche) incorporation assay as previously described $[23,26]$.

For CCK-8, VSMCs were seeded in 96-well plates (Corning) at $6 \times 10^{3}$ cells per well in $200 \mu \mathrm{l}$ culture medium. Following synchronization by DMEM with $0.1 \%$ FBS for $24 \mathrm{~h}$, VSMCs were pretreated with various concentrations of 2,4-PDCA $(0,0.125,0.25,0.5$ and $1.0 \mathrm{mM})$ or siRNA-JMJD2A (20nM) and then stimulated with HG. After $24 \mathrm{~h}$ of stimulation, $20 \mu \mathrm{l}$ of CCK-8 was added, and the absorbance was measured at $450 \mathrm{~nm}$. The NG group acted as control.

For BrdU incorporation assay, BrdU solution was introduced into each well at the final concentration of $10 \mu \mathrm{M}$. After incubation for $4 \mathrm{~h}$, cells were fixed with Fixing Solution at room temperature for $30 \mathrm{~min}$. The BrdU label was detected using a peroxidase-conjugated mouse anti-BrdU monoclonal antibody and followed by the reaction with the substrate solution. The absorbance of the samples was measured using a microplate reader at $450 \mathrm{~nm}$.

\section{Cell migration}

VSMCs migration was assessed using a transwell chamber assay ( $8 \mu \mathrm{m}$, Corning) and wound healing assay as described before [27].

For transwell chamber assay, $1 \times 10^{5}$ serum starved cells were pretreated with $1.0 \mathrm{mM}$ 2,4-PDCA or $20 \mathrm{nM}$ siRNA-JMJD2A and seeded into the upper chamber in $200 \mu \mathrm{l}$ serum-free medium. $600 \mu \mathrm{I}$ DMEM containing NG or HG was added to the lower chamber. Twenty-four hours later, the non-migrating cells were subsequently removed with a cotton swab and the migrated cells were fixed in methanol and stained with $0.5 \%$ crystal violet. The number of migrated cells was counted in ten randomly selected fields under a microscope at $100 \times$ magnification.

For wound healing assay, the confluent monolayer VSMCs treated as mentioned above were wounded with a yellow tip and washed with phosphate buffered saline (PBS) to remove debris. After stimulation with HG for $24 \mathrm{~h}$, the images of migration were photographed by light microscope under a magnification of $100 \mathrm{x}$ and quantified as percentage of wound closure.

Chromatin immunoprecipitation (ChIP) assay

ChIP assays were performed and ChIP-enriched DNA was analyzed by real-time qPCR as previously described [28]. Briefly, the cells were fixed with $1 \%$ formaldehyde, washed and lysed. The cell lysates were 


\section{Cellular Physiology Cell Physiol Biochem 2015;37:719-734 \\ \begin{tabular}{c|c|c|}
\cline { 2 - 2 } DOI: 10.1159/000430390 & O 2015 S. Karger AG, Basel \\
\hline
\end{tabular} \\ and Biochemistry Published online: September 11, 2015 www.karger.com/cpb \\ Qi et al.: JMJD2A Inhibition Attenuates Neointimal Hyperplasia in Diabetic Rats}

sonicated into fragmented chromatin approximately 400-500 bp in length, diluted in ChIP dilution buffer and subjected to immunoprecipitation with IgG (Santa cruz) or anti-H3K9me3 antibodies (Abcam) overnight at $4^{\circ} \mathrm{C}$. Immune complexes were collected, washed and eluted with buffer. Protein-DNA crosslinks were reversed overnight at $65^{\circ} \mathrm{C}$, and the DNA was extracted. ChIP-enriched DNA samples were analyzed by real-time qPCR using primers near the NFKB-binding sites specific for IL- 6 or MCP-1 promoters. The data were analyzed using the $2^{-\triangle \triangle \mathrm{Ct}}$ method and normalized with input samples. The results were expressed as a percentage of NG control group. The primer sequences are listed: MCP-1 promoter (forward, 5'-GCACTTACTCAGCAGATTC-3'; reverse, 5'-GCCTCAGCCTTTTATTGT-3'); IL-6 promoter (forward, 5'-TCACATTGTGCAATCTTAA-3'; reverse, 5'-ATGGAGTTGACTTTCGTT-3').

\section{Diabetic rat model and carotid artery balloon injury}

Diabetic rat model was constructed using a combination of high-fat diet and low-dose streptozotocin (STZ, Sigma) injection as previously described [29, 30]. Male SD rats (200-250 g) were given high-fat diets (60\% fat) for 4 weeks and received a single intraperitoneal injection of streptozotocin (35 mg/kg). Two days later, their blood glucose levels were measured (OneTouch® UltraEasy) and rats with non-fasting blood glucose level of $>15 \mathrm{mM}$ were used for later experiments. Two weeks later, we implemented the rat carotid artery balloon-injury model as described previously [31, 32]. The rats were anesthetized via an intraperitoneal injection of pentobarbital ( $40 \mathrm{mg} / \mathrm{kg}$, Sigma). Following the blunt dissection of the left carotid artery, an arterial balloon catheter (balloon diameter $1.5 \mathrm{~mm}$, balloon length $20 \mathrm{~mm}$, Medtronic) was inserted through the external carotid arteriotomy. The catheter was inflated slowly until moderate resistance was achieved and pulled down the entire length of the common carotid artery from the incision to the aortic arch 3 times. The catheter was subsequently deflated and withdrawn, and the external carotid branch was ligated.

\section{Metabolic measurements}

Rats were fasted overnight and anaesthetized with pentobarbital sodium. Blood samples were collected from external jugular vein into SST TUBE (BD) and centrifuged at $3000 \mathrm{RPM}$ for $10 \mathrm{~min}$ at $4^{\circ} \mathrm{C}$. Serum was collected for the detection of glucose, total cholesterol, triglyceride, high-density lipoprotein cholesterol (HDL-C) and low-density lipoprotein cholesterol (LDL-C) using a standard commercial enzymatic assay. Insulin was measured using a rat insulin ELISA kit (Millipore, Billerica, MA) according to the manufacturer's instructions. Insulin tolerance test (ITT) was performed to detect insulin resistance as described before [33]. The fasted rats were intraperitoneally injected with $0.2 \mathrm{U} / \mathrm{kg}$ of insulin. Blood glucose was determined at $0,10,20,30$ and $60 \mathrm{~min}$ after injection. Insulin sensitivity was represented by the glucose disappearance rate, the average slope $K$-value in the fitting curve.

\section{Morphometric analysis}

Rat carotid arteries were harvested following euthanasia on the $28^{\text {th }}$ day after the operations and fixed with $4 \%$ paraformaldehyde for $48 \mathrm{~h}$, followed by ethanol dehydration and paraffin embedding a histological analysis. Five thin $(4 \mu \mathrm{m})$ cross-sections were obtained from the middle of the injured artery at $1 \mathrm{~mm}$ intervals and stained with hematoxylin and eosin. The neointima area and the intima/media ratio were measured using Image Pro-Plus 6.0 (USA). To evaluate the proliferative activity and H3K9me3 expression of cells at the balloon injury sites, immunohistochemical staining with an antibody against proliferating cell nuclear antigen (PCNA, Bioss) or H3K9me3 (Abcam) was performed. For the immunohistochemistry analysis, the sections were incubated with an antibody against H3K9me3 (Abcam) and proliferating cell nuclear antigen (PCNA, Bioss). The number of positively stained cells quantified from five random fields under $200 \mathrm{x}$ magnification.

\section{Quantitative real-time PCR}

The mRNA expressions of MCP-1 and IL- 6 both in the cells and the vessels were assessed using quantitative real-time PCR [34]. Total RNA was extracted using a PicoPure RNA isolation kit (Applied Biosystems) according to the manufacturer's instructions and reverse transcribed into cDNA using a First-Strand Synthesis System (Invitrogen). This protocol was performed using the SYBR system in ABI Prism 7500 Sequence Detection System (Applied Biosystems,). Each sample was collected and analyzed in triplicate. The data were normalized to $\beta$-actin expression and analyzed by the $2^{-\Delta \Delta \mathrm{Ct}}$ method. The primer 


\section{Cellular Physiology Cell Physiol Biochem 2015;37:719-734

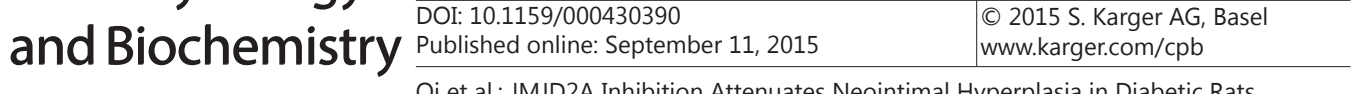

sequences used in this study are summarized as below: MCP-1 (forward, 5'-ATGCAGGTCTCTGTCACGCT-3'; reverse, 5'-GGTGCTGAAGTCCTTAGGGT-3'); IL-6 (forward, 5'-CAAAGCCAGAGTCATTCAGAGC-3'; reverse, 5'-GGTCCTTAGCCACTCCTTCTGT- 3'); $\beta$-actin (forward, 5'-ATGCCATCCTGCGTCTGGACCTGGC-3'; reverse, 5'-AGCATTTGCGGTGCACGATGGAGG-3')

Western blotting

Total protein was extracted from cells and carotid arteries using the protein extraction kit (Beyotime) containing $1 \mathrm{mM}$ PMSF and $10 \mathrm{mM}$ phosphatase inhibitor (Roche). Total protein was quantified using a BCA protein assay kit (Beyotime). Equal amount ( $40 \mu \mathrm{g}$ ) was separated by SDS-PAGE and transferred to polyvinylidene difluoride (PVDF) membranes. The PVDF membranes were subsequently blocked and incubated with antibodies against JMJD2A (Sigma), H3K9me3 (Abcam), MCP-1 (Abcam), IL-6 (Abcam) and $\beta$-actin (Affbiotech) overnight at $4^{\circ} \mathrm{C}$. After being washed three times for $10 \mathrm{~min} \times 3$ times, the membranes were incubated with horseradish peroxidase (HRP) conjugated secondary antibodies (Bioss) for $2 \mathrm{~h}$ at room temperature and subsequently analyzed using ECL reagent (Pierce).

Statistical analysis

All results were analyzed using either Student's t-test for between-group comparisons or the 1-way ANOVA for multiple comparisons using SPSS 13.0. All data are presented as means \pm SEM. A p-value $<0.05$ was considered significant.

\section{Results}

JMJD2A protein levels are increased in HG-stimulated VSMCs and balloon-injured carotid arteries of diabetic rats, whereas $\mathrm{H} 3 \mathrm{~K} 9 \mathrm{me} 3$ levels are decreased

In vitro, serum-depleted VSMCs were stimulated with HG, palmitate and insulin for 0-24 $\mathrm{h}$ to mimic diabetic state. Immunoblotting demonstrated JMJD2A was increased in a timedependent manner under HG stimulation, which peaked at approximately $6 \mathrm{~h}$ and continued to $24 \mathrm{~h}$. However H3K9me3, the main substrate of JMJD2A, was decreased and reached its minimum at $24 \mathrm{~h}$ (Fig. 1A). No significant change in JMJD2A or H3K9me3 was detected under the stimulation of palmitate or insulin (Fig. 1B-C). We next explored the expression of JMJD2A and H3K9me3 in carotid arteries of diabetic rats with or without balloon injury. As shown in Fig. 1D, both in balloon-injured and un-injured carotid arteries from diabetic rats, JMJD2a protein level was significantly increased whereas H3K9me3 was decreased. These results indicated that JMJD2A protein levels were increased and H3K9me3 levels were decrease in HG-stimulated VSMCs and balloon-injured carotid arteries of diabetic rats.

JMJD2A inhibition suppressed HG-induced proliferation, migration via the down-regulated inflammation in VSMCS

We probed the potential influence of JMJD2A inhibition on HG-treated VSMCs. The enzymatic activity of JMJD2A was blocked using the chemical inhibitor 2, 4-PDCA. HG stimulated VSMCs proliferation witch was increased almost 1.6 folds compared with NG control (Fig. 2A-B). 2,4-PDCA inhibited HG-induced proliferation in a concentrationdependent manner (Fig. 2A-B). The peak inhibitory effect was observed at the concentration of $1.0 \mathrm{mM}$. VSMCs exhibited more active migratory capability under HG stimulation that was nearly increased by 2.1 fold (Fig. 2C-D). And pretreatment of 2,4-PDCA (1.0 mM) abolished HG-induced migration as well (Fig. 2C-D). To guarantee the specificity of JMJD2A inhibition, siRNA-JMJD2A was utilized to achieve JMJD2A knockdown. The silencing efficiency was determined by western blotting. Approximate 40\% reduction was achieved in VSMCs transfected with 20 nM siRNA-JMJD2A (Fig. 2E), so we have chosen 20 nM siRNA-JMJD2A for the subsequent experiments. Consistent with the results of 2, 4-PDCA, siRNA-JMJD2A suppressed the HG-induced proliferation and migration in VSMCs (Fig. 2F-I). In addition, the expressions of inflammatory genes were examined using both quantitative real-time PCR and western blotting. There was a significant increase in mRNA and protein expression of 


\section{Cellular Physiology Cell Physiol Biochem 2015;37:719-734 \begin{tabular}{l|l|l}
\hline DOI: 10.1159/000430390 & O 2015 S. Karger AG, Basel
\end{tabular} \\ Qi et al.: JMJD2A Inhibition Attenuates Neointimal Hyperplasia in Diabetic Rats}

Fig. 1. Expression of JMJD2A and $\mathrm{H} 3 \mathrm{~K} 9 \mathrm{me} 3$ in VSMCs and carotid arteries. (A-C) Protein expression of JMJD2A and H3K9me3 in VSMCs under diabetic condition. Serum-depleted VSMCs were treated with HG (A), 400 $\mu \mathrm{M}$ palmitate (B) and $100 \mathrm{nM}$ insulin (C) for $0-24 \mathrm{~h}$. Total protein expression of JMJD2A and H3K9me3 were assessed by western blot and results were expressed as densitometry ratio $(\mathrm{n}=3) .{ }^{*} p<0.05$ vs. 0h. (D) Western blot analysis of JMJD2A and H3K9me3 in carotid arteries of normal (Nor) or diabetic (DM) rats accepting (injury) or not to accepting (uninjury) balloon injury $(\mathrm{n}=6)$. ${ }^{\#} p<0.05$ vs. uninjury normal group; \#\# $p<0.05$ vs. injury normal group.
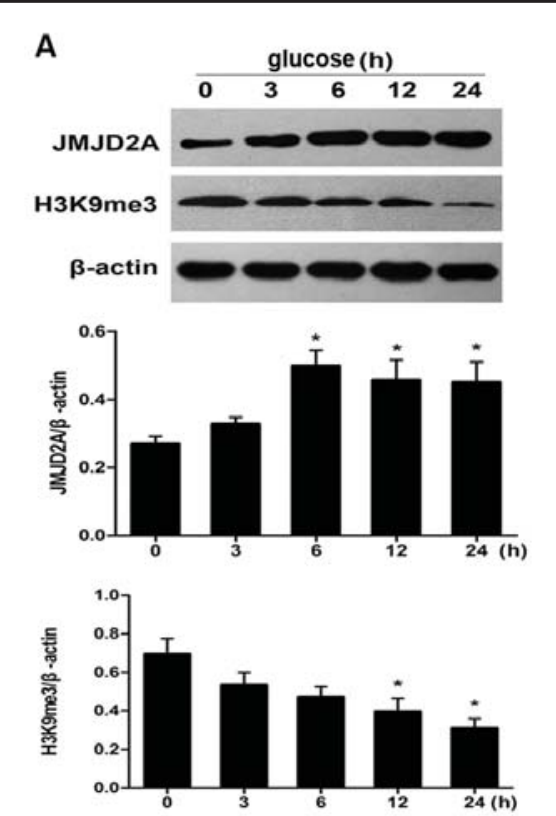

c
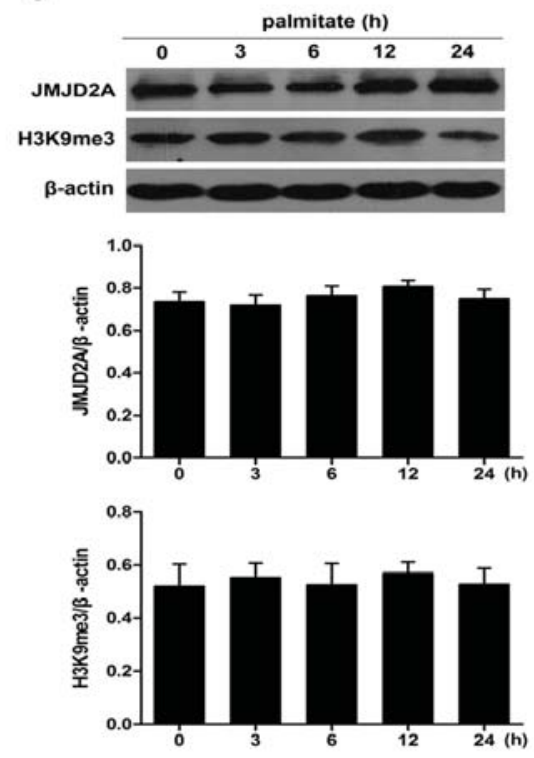
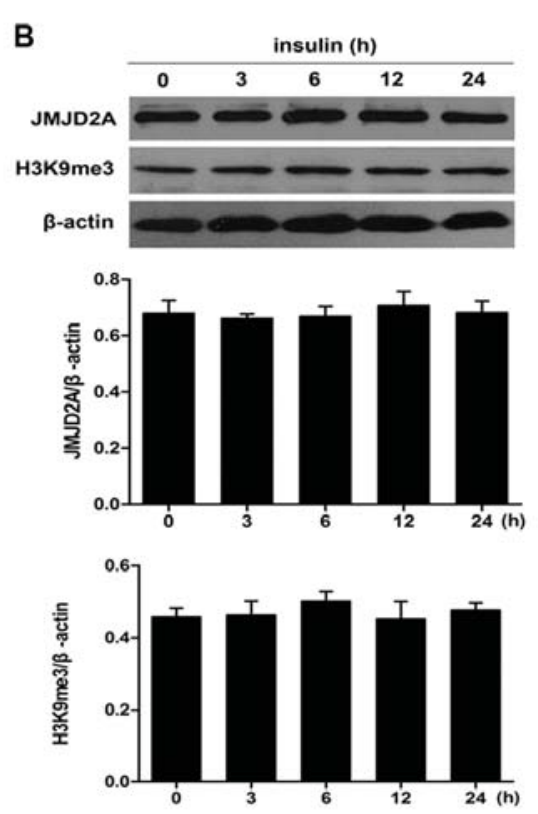

D
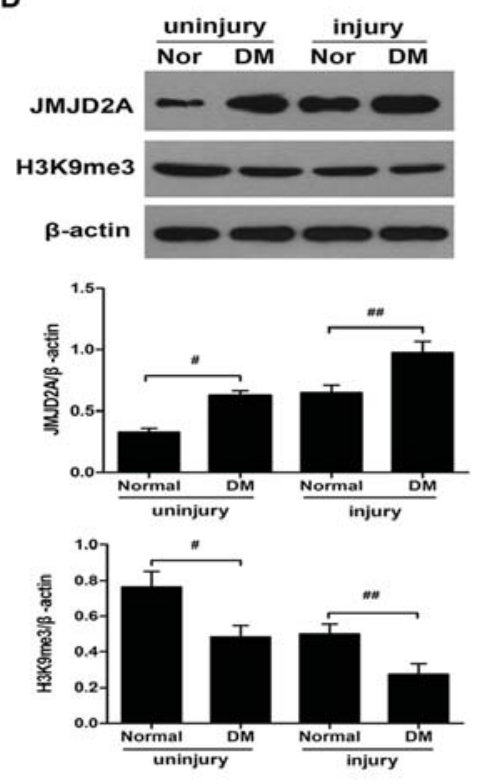

MCP-1 and IL-6 in HG-stimulated VSMCs (Fig. 2J-K). And both 2, 4-PDCA and siRNA-JMJD2A reduced the mRNA and protein expressions of MCP-1 and IL-6 (Fig. 2J-K). These results revealed that the JMJD2A inhibition suppresses HG-induced proliferation, migration and inflammation in VSMCs.

The inflammation plays a pivotal role in the physiopathology of occlusive vascular disease, contributing to VSMC proliferation and migration. To verify whether if the suppressed proliferation and migration by JMJD2A inhibition is mediated by the decreased MCP-1 and IL-6, the neutralizing antibodies against MCP-1 (Abcam, 3ng/ml) and IL-6 (Abcam, 3ng/ml) were utilized to offset their potential effects. VSMCs pretreated with antibodies exhibited mild proliferation and migration in response to HG (Fig. 3). These results informed that JMJD2A inhibition suppresses HG-stimulated proliferation and migration in VSMCs through reducing inflammatory expression. 


\section{Cellular Physiology Cell Physiol Biochem 2015;37:719-734 \begin{tabular}{c|c|c|}
\cline { 2 - 2 } DOI: 10.1159/000430390 & O 2015 S. Karger AG, Basel
\end{tabular} and Biochemistry Published online: September 11, 2015 www.karger.com/cpb

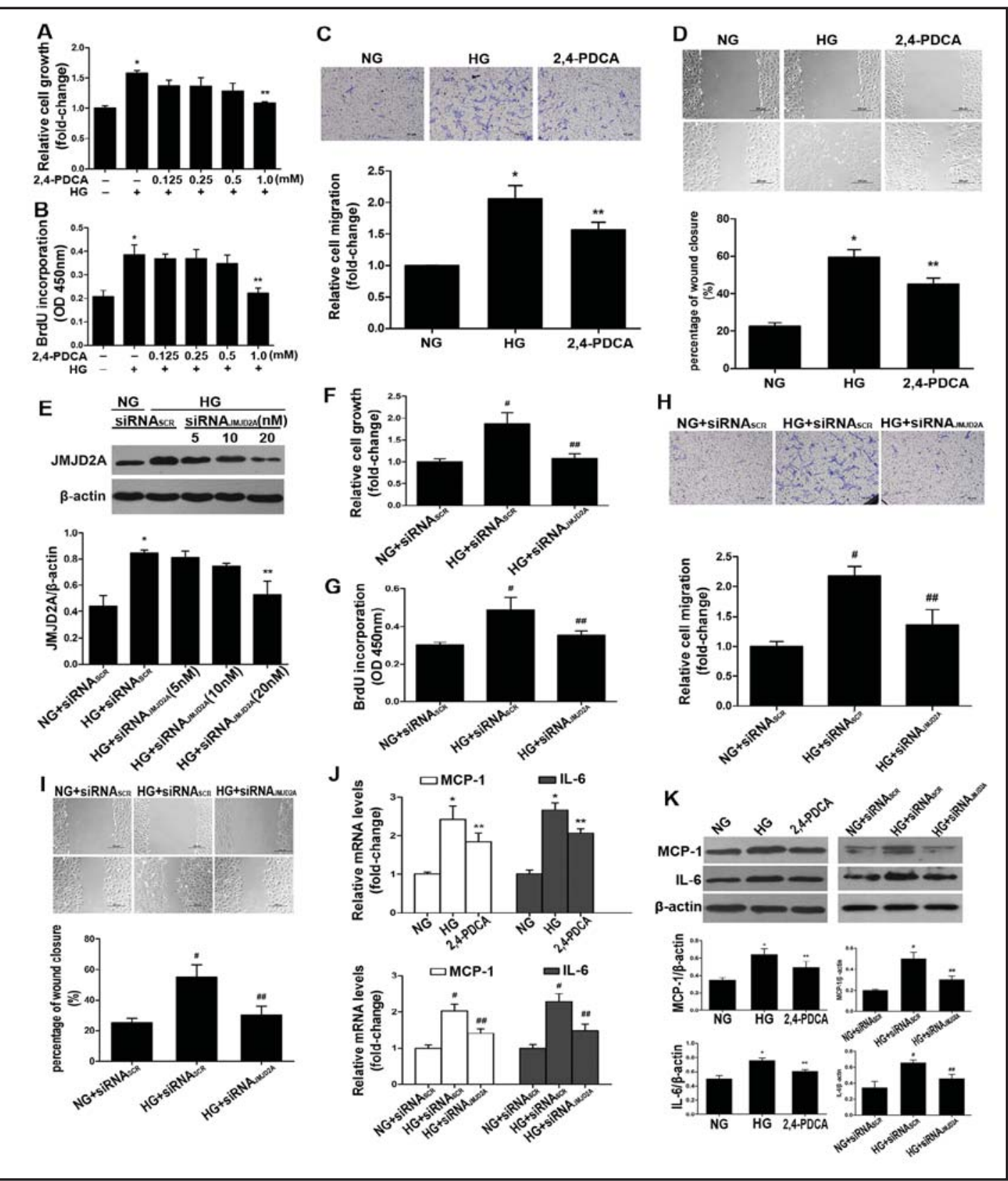

Fig. 2. JMJD2A inhibition suppressed HG-induced proliferation, migration and inflammation in VSMCs. (AD) VSMCs were pretreated with 2,4-PDCA for $4 \mathrm{~h}$ at concentrations varying from 0 to $1.0 \mathrm{mM}$ and stimulated with HG (25mM) for another 24h (n=3). VSMCs proliferation was detected using CCK-8 (A) and BrdU (B). VSMCs migration was determined by transwell (C) and wound healing (D) assays. ${ }^{*} p<0.05$ vs. NG group; ${ }^{* *} p<0.05$ vs. HG group. (E) VSMCs were transfected with siRNA-scrambled (siRNA SCR $_{\text {) }}$ ) and siRNA-JMJD2A (siRNA ${ }_{\text {IMID2A }}$ 5, 10 and $20 \mathrm{nM}$ ). Western blot was performed to analyze the expression of JMJD2A (N=3). ${ }^{*} p<0.05$ vs. NG+siRNA SCR $_{\text {group; }}{ }^{* *} p<0.05$ vs. $\mathrm{HG}+\mathrm{siRNA}_{\mathrm{SCR}}$ group. (F-I) VSMCs were transfected with 20 $\mathrm{nM} \mathrm{siRNA}_{\mathrm{SCR}}$ or siRNA $_{\mathrm{JMJD2A}}$ for $48 \mathrm{~h}$, and then stimulated with or without HG for another $24 \mathrm{~h}(\mathrm{n}=3)$. VSMCs proliferation was detected using CCK-8 (F) and BrdU (G). VSMCs migration was determined by transwell (H) and wound healing (I) assays. ${ }^{\#} p<0.05$ vs. $N G+$ siRNA $_{\text {SCR }}$ group; ${ }^{\# \#} p<0.05$ vs. HG+siRNA SCR $_{\text {group. (J-K) VSMCs }}$ were pre-treated with $1.0 \mathrm{mM}$ 2,4-PDCA or $20 \mathrm{nM} \mathrm{siRNA}_{\mathrm{SCR}} / \mathrm{siRNA}_{\mathrm{JMJD2A}}$ and stimulated with or without HG for another 16h. the expressions of MCP-1 and IL- 6 were detected using real-time PCR (J) and western blot (K) (n=3). ${ }^{*} p<0.05$ vs. NG group; ${ }^{* *} p<0.05$ vs. HG group; ${ }^{\#} p<0.05$ vs. NG+siRNA SCR group; ${ }^{\# \#} p<0.05$ vs. $\mathrm{HG}+$ siRNA $_{\mathrm{SCR}}$ group. ${ }^{\#} p<0.05$ vs. HG+2,4-PDCA group; ${ }^{\# \#} p<0.05$ vs. HG+siRNA ${ }_{\text {JMJD2A }}$ group. 


\section{Cellular Physiology Cell Physiol Biochem 2015;37:719-734 \begin{tabular}{l|l|l|}
\hline DOI: 10.1159/000430390 & O 2015 S. Karger AG, Basel
\end{tabular}

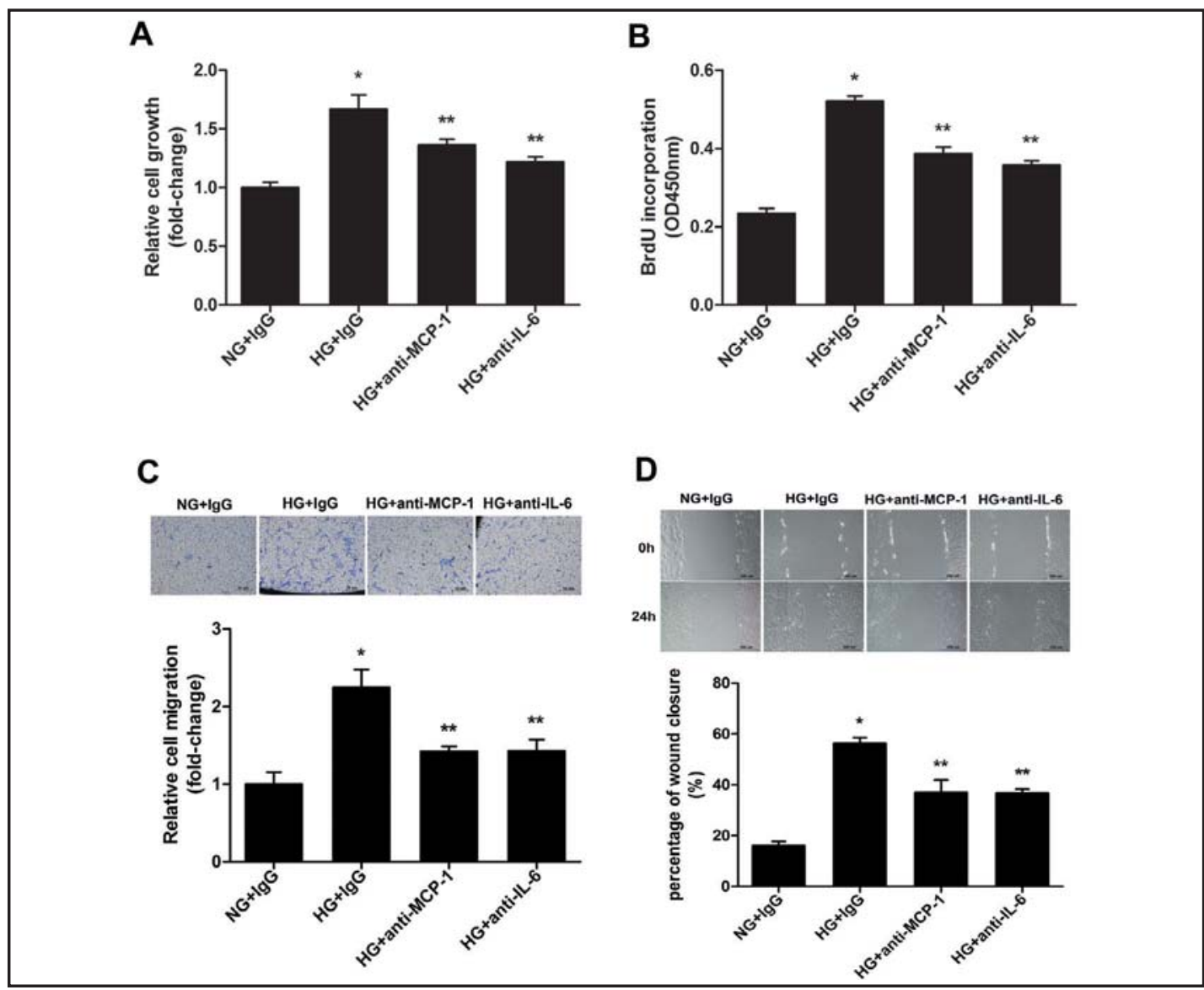

Fig. 3. JMJD2A inhibition suppresses HG-stimulated proliferation and migration in VSMCs through reducing inflammatory response. VSMCs were pretreated with the neutralizing antibody against MCP-1 (anti-MCP-1, $3 \mathrm{ng} / \mathrm{ml}$ ) and IL-6 (anti-IL-6, 3ng/ml) and stimulated with HG for $24 \mathrm{~h}(\mathrm{n}=3)$. VSMCs proliferation was detected using CCK-8 (A) and BrdU (B). VSMCs migration was determined by transwell (C) and wound healing (D) assays. ${ }^{*} p<0.05$ vs. NG+IgG group; ${ }^{* *} p<0.05$ vs. $\mathrm{HG}+\operatorname{IgG}$ group.

JMJD2A inhibition represses the inflammatory expression in HG-stimulated VSMCs via the restoration of $\mathrm{H} 3 \mathrm{~K} 9 \mathrm{me} 3$ at promoters

H3K9me3, the main substrate of JMJD2A, generally correlates with gene repression. To determine whether the down-regulated inflammation is due to the induction of $\mathrm{H} 3 \mathrm{~K} 9 \mathrm{me} 3$ after JMJD2A inhibition, western blotting was performed to detect the total H3K9me3 firstly. As shown in Fig. 4A-C, H3K9me3 was decreased in HG-treated VSMCs, whereas 2, 4-PDCA and siRNA-JMJD2A restored H3K9me3 levels. Furthermore, ChIP-qPCR assays suggested that H3K9me3 at the promoters of MCP-1 and IL- 6 was reduced in VSMCs under HG condition but was reverted after the pretreatment of 2, 4-PDCA and siRNA-JMJD2A (Fig. 4D-G). These results indicate that the increased inflammatory expression in HG-treated VSMCs may be due to the reduction of repressive marker, $\mathrm{H} 3 \mathrm{~K} 9 \mathrm{me} 3$, and JMJD2A inhibition represses inflammatory expression via the restoration of $\mathrm{H} 3 \mathrm{~K} 9 \mathrm{me} 3$.

\section{JMJD2A inhibition alleviates neointimal formation in diabetic rats}

We have constructed diabetic rat model successfully and the metabolic changes were summarized in Table 1. To explore the potential effect of JMJD2A on vascular remodeling in balloon-injured diabetic rats, we both employed a daily intraperitoneal injection of 2 , 4-PDCA and a transfection of siRNA-JMJD2A. The transfection efficiency in vivo was validated by western blot $48 \mathrm{~h}$ after transfection. As shown in Fig. 5A, siRNA-JMJD2A depleted JMJD2A expression in the injured arteries. A histomorphological analysis demonstrated that, 


\section{Cellular Physiology Cell Physiol Biochem 2015;37:719-734 \begin{tabular}{ll|l}
\hline DOI: 10.1159/000430390 & O 2015 S. Karger AG, Basel
\end{tabular}

Fig. 4. JMJD2A inhibition represses the inflammatory response in HG-stimulated VSMCs via up-regulation of H3K9me3. VSMCs were pre-treated with 1.0 mM 2,4-PDCA or $20 \mathrm{nM}$ siRNA $_{\text {SCR }} /$ siRNA $_{\text {JMJD2A }}$ and stimulated with or without HG for another 16h. (A-C) The total protein level of H3K9me3 was determined by western blot $(n=3)$. ${ }^{*} p<0.05$ vs. NG group; ${ }^{* *} p<0.05$ vs. HG group; ${ }^{\#} p<0.05$ vs. NG+siRNA group; ${ }^{\# \#} p<0.05$ vs. HG+siRNA $_{\text {SCR }}$ group. (D-G) The H3K9me3 levels at promoters of MCP-1 and IL-6 were quantified with ChIPPCR (n=3). ${ }^{*} p<0.05$ vs. NG group; ${ }^{* *} p<0.05$ vs. HG group; ${ }^{\#} p<0.05$ vs. NG+siRNA $_{\mathrm{SCR}}$ group; ${ }^{\# \#} p<0.05$ vs. $\mathrm{HG}+\mathrm{siRNA}_{\mathrm{SCR}}$ group.
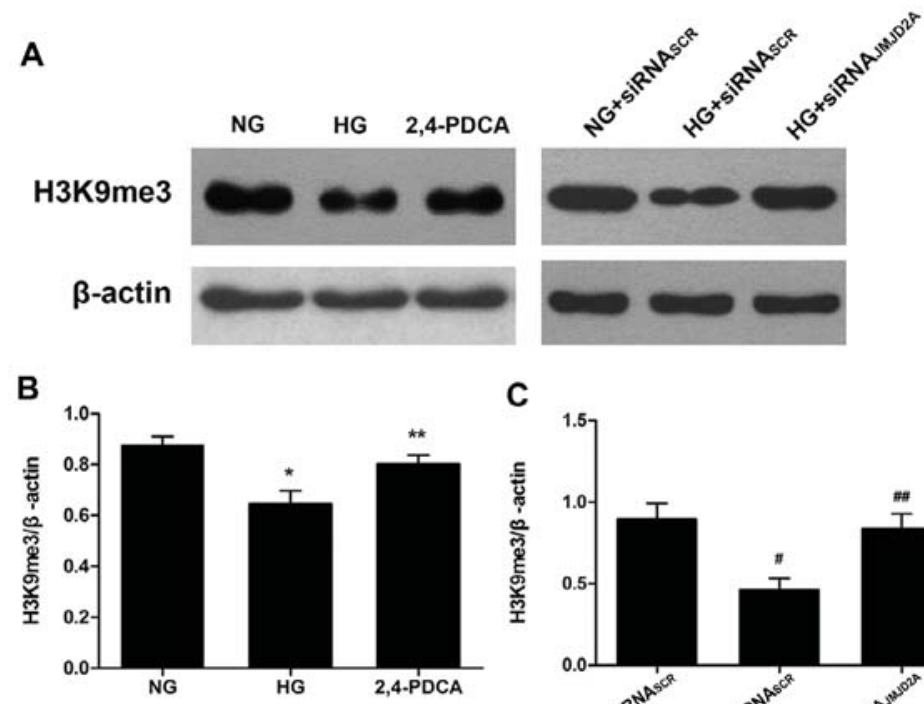

D
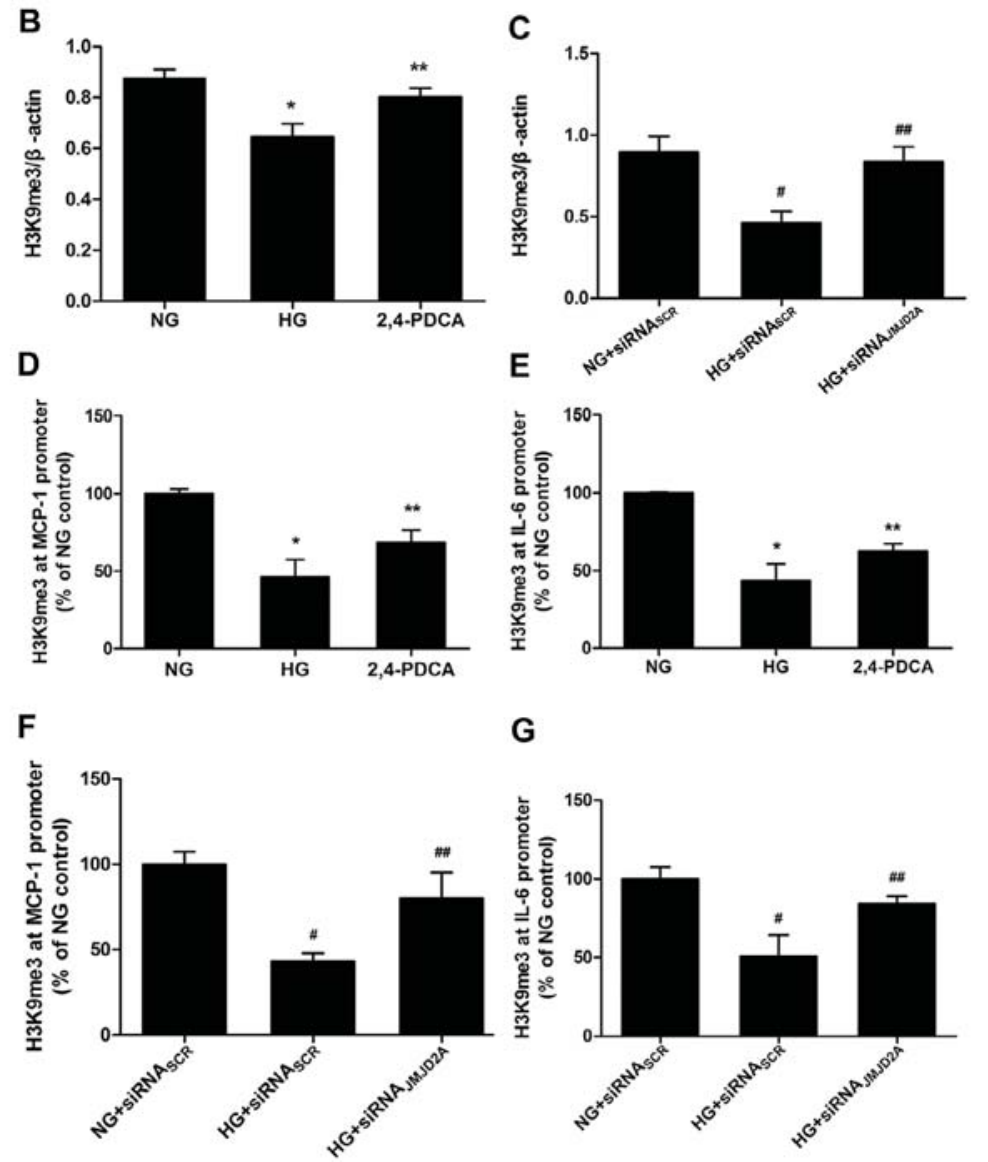

Table 1. Metabolic changes in experimental rats. Data were presented as Mean \pm SEM $(n=10)$. Nor: normal rats; DM: diabetic rats; HDL-C: high-density lipoprotein cholesterol. LDL-C: low-density lipoprotein cholesterol. $* p<0.05$ vs. normal rats

\begin{tabular}{lccccccc}
\hline & $\begin{array}{c}\text { Triglyceride } \\
(\mathrm{mmol} / \mathrm{L})\end{array}$ & $\begin{array}{c}\text { Cholesterol } \\
(\mathrm{mmol} / \mathrm{L})\end{array}$ & $\begin{array}{c}\text { HDL-C } \\
(\mathrm{mmol} / \mathrm{L})\end{array}$ & $\begin{array}{c}\text { LDL-C } \\
(\mathrm{mmol} / \mathrm{L})\end{array}$ & $\begin{array}{c}\text { Glucose } \\
(\mathrm{mmol} / \mathrm{L})\end{array}$ & $\begin{array}{c}\text { Insulin } \\
(\mathrm{ng} / \mathrm{ml})\end{array}$ & K-value \\
\hline Nor & $0.98 \pm 0.16$ & $1.01 \pm 0.18$ & $1.18 \pm 0.14$ & $0.63 \pm 0.16$ & $5.61 \pm 0.45$ & $0.45 \pm 0.13$ & $55.65 \pm 2.54$ \\
DM & $2.53 \pm 0.27^{*}$ & $2.80 \pm 0.30^{*}$ & $0.76 \pm 0.22$ & $1.22 \pm 0.04^{*}$ & $18.58 \pm 1.65^{*}$ & $0.60 \pm 0.11$ & $31.22 \pm 2.04^{*}$ \\
\hline
\end{tabular}

compared with the saline or scrambled control, both 2, 4-PDCA and siRNA-JMJD2A reduced neointimal area and I/M ratio in the injured arteries 28 days after injury (Fig. 5B-C). The maximum inhibitory effect of 2, 4-PDCA was observed at a concentration of $7.5 \mathrm{mg} / \mathrm{kg} / \mathrm{d}$. In addition, cell proliferation in the neointima was evaluated using immunohistochemical staining for PCNA. As shown in Fig. 5D-E, administration of 2, 4-PDCA (7.5 mg/kg/d) and JMJD2A-siRNA reduced the percentage of PCNA-positive cells in the neointima compared with saline or scrambled control, manifesting that the inhibition of JMJD2A markedly suppressed VSMCs proliferation.

\section{KARGER}




\section{Cellular Physiology Cell Physiol Biochem 2015;37:719-734 \begin{tabular}{l|l|l|}
\hline DOI: 10.1159/000430390 & O 2015 S. Karger AG, Basel
\end{tabular} and Biochemistry Published online: September 11, $2015 \quad$ www.karger.com/cpb}

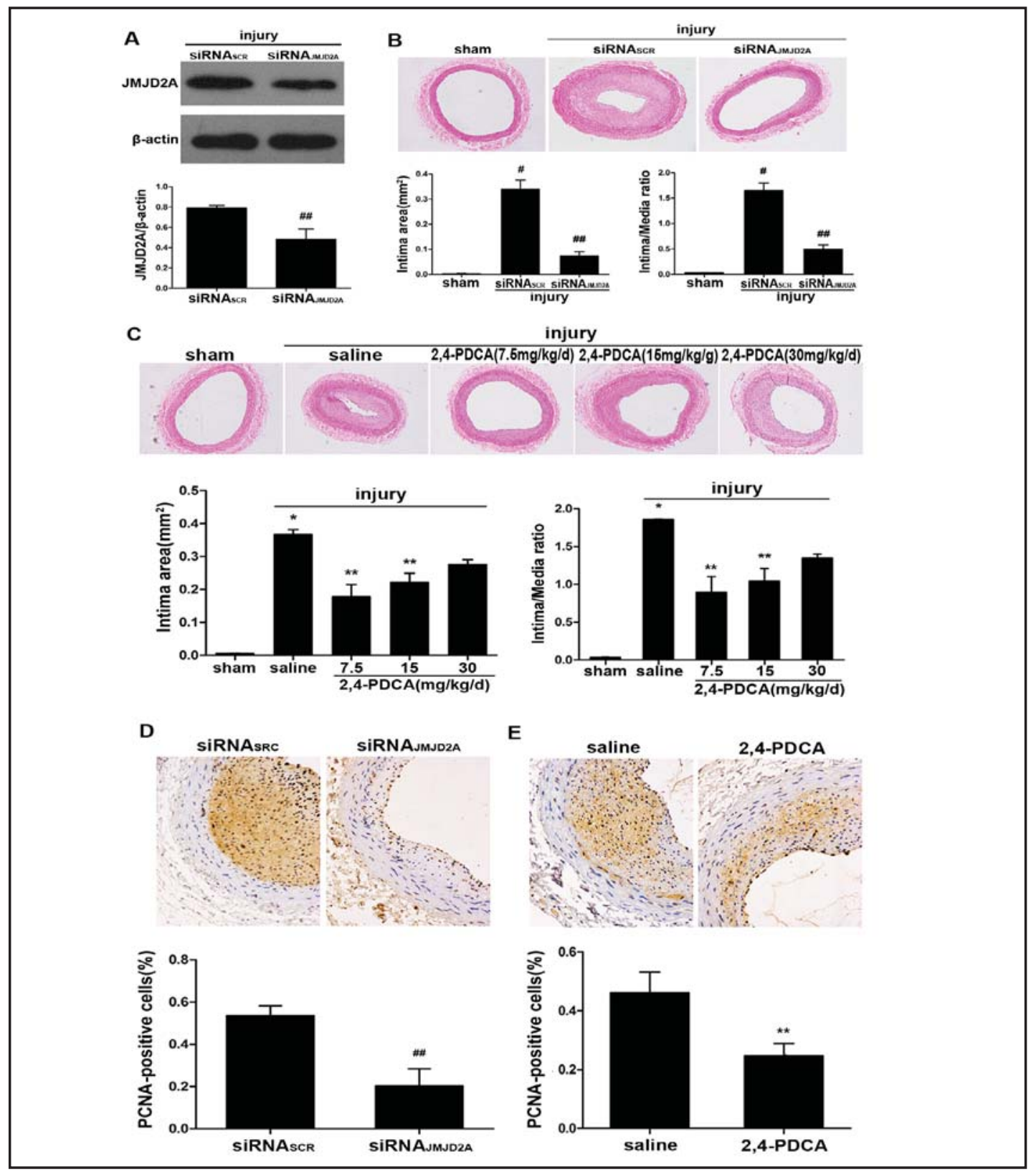

Fig. 5. Inhibition of JMJD2A alleviates neointimal formation in diabetic rats. (A) Diabetic rats experienced balloon injury were transfected with siRNA ${ }_{\mathrm{SCR}}$ or siRNA $\mathrm{JMJD2A}_{\mathrm{Im}}$ imediately. Two days later rats were sacrificed and carotid arteries were collected. The protein level of JMJD2A was detected by western blot $(n=6)$. ${ }^{\# \#} p<0.05$ vs. injury+siRNA ${ }_{\text {SCR }}$ group. (B) Hematoxylin eosin-stained carotid arteries survey the effects of siRNA-JMJD2A on neointimal formation in balloon injured carotid arteries. Quantitative analysis of intimal area and ratio of intima to media were calculated 28 days after balloon injury $(n=6) .{ }^{*} p<0.05$ vs. sham group; ${ }^{\# \#} p<0.05$ vs. injury+siRNA ${ }_{\mathrm{SCR}}$ group. (C) Hematoxylin eosin-stained carotid arteries survey the effects of 2,4-PDCA $(7.5 / 15 / 30 \mathrm{mg} / \mathrm{kg} / \mathrm{d})$ on neointimal formation in balloon injured carotid arteries. Quantitative analysis of intimal area and ratio of intima to media were calculated 28 days after balloon injury $(\mathrm{n}=6)$. ${ }^{*} p<0.05$ vs. sham group; ${ }^{* *} p<0.05$ vs. injury+saline group. (D) Immumohistochemical staining of PCNA detected the inhibitory effects of siRNA-JMJD2A on cell proliferation in injured carotid arteries. PCNA labeled nuclei stained as dark brown $(\mathrm{n}=6) .{ }^{\# \#} p<0.05$ vs. injury+siRNA ${ }_{\mathrm{SCR}}$ group. (E) Immumohistochemical staining of PCNA detected the inhibitory effects of 2,4-PDCA on cell proliferation in injured carotid arteries. Intraperitoneal injection of $7.5 \mathrm{mg} / \mathrm{kg} . \mathrm{d}$ 2,4-PDCA was accomplished 28 days after balloon injury. PCNA labeled nuclei stained as dark brown $(\mathrm{n}=6) .{ }^{* *} p<0.05$ vs. injury+saline group. 


\section{Cellular Physiology Cell Physiol Biochem 2015;37:719-734 \begin{tabular}{l|l|l|}
\hline DOI: 10.1159/000430390 & O 2015 S. Karger AG, Basel
\end{tabular} and Biochemistry Published online: September 11, $2015 \quad$ www.karger.com/cpb
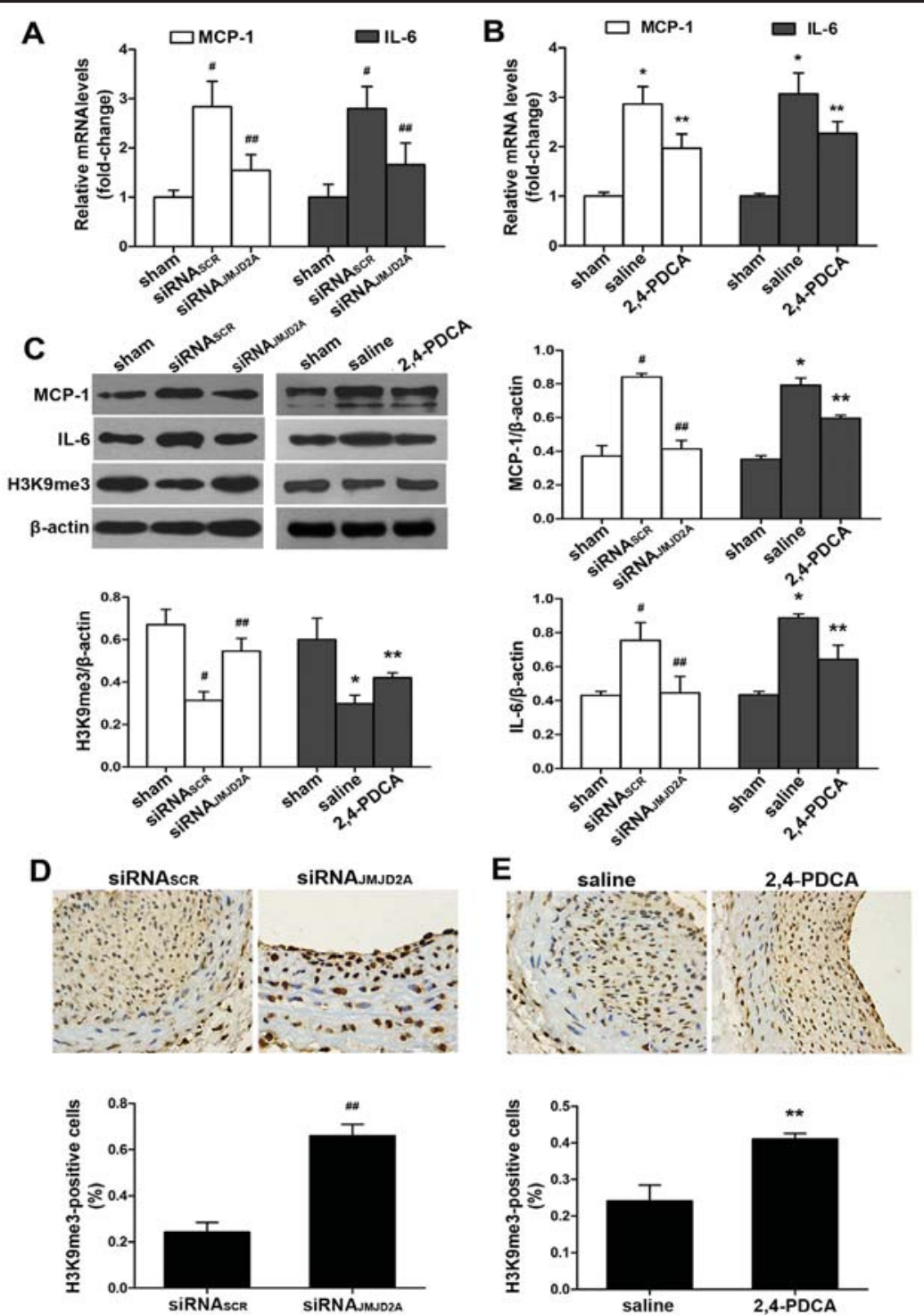

Fig. 6. Inhibition of JMJD2A restores $\mathrm{H} 3 \mathrm{~K} 9 \mathrm{me} 3$ and suppresses the inflammatory response in injured arteries of diabetic rats. (A-B) Rat carotid arteries were harvested by euthanasia on the $7^{\text {th }}$ day after operation to detect the effects of siRNA-JMJD2A (A) and 2,4-PDCA (B) on mRNA expressions of MCP-1 and IL-6 in vivo by real-time PCR $(\mathrm{n}=6) .{ }^{\#} p<0.05$ vs. sham group; ${ }^{\# \#} p<0.05$ vs. injury+siRNA $A_{\mathrm{SCR}}$ group. ${ }^{*} p<0.05$ vs. sham group; ${ }^{* *} p<0.05$ vs. injury+saline group. (C) Rat carotid arteries were harvested by euthanasia on the $7^{\text {th }}$ day after operation to detect the effects of JMJD2A inhibition on protein expressions of MCP-1, IL-6 and H3K9me3 in vivo by western blot(n=6). ${ }^{\#} p<0.05$ vs. sham group; ${ }^{\# \#} p<0.05$ vs. injury+siRNA SCR $_{\text {group. }}{ }^{*} p<0.05$ vs. sham group; ${ }^{* *} p<0.05$ vs. injury+saline group. (D) Immumohistochemical staining of H3K9me3 detects the effects of siRNA-JMJD2A on the level of H3K9me3 in injured carotid arteries 28 days after operation. H3K9me3 labeled nuclei stained as dark brown (n=6). ${ }^{\# \#} p<0.05$ vs. injury+siRNA ${ }_{\mathrm{SCR}}$ group. (E) Immumohistochemical staining of H3K9me3 detects the effects of 2,4-PDCA on the level of H3K9me3 in injured carotid arteries. Intraperitoneal injection of $7.5 \mathrm{mg} / \mathrm{kg} . \mathrm{d} 2,4$-PDCA was accomplished 28 days after balloon injury. H3K9me3 labeled nuclei stained as dark brown (n=6). ${ }^{*} p<0.05$ vs. sham group; ${ }^{* *} p<0.05$ vs. injury+saline group.

JMJD2A inhibition restores H3K9me3 and suppresses the inflammatory response in injured arteries of diabetic rats

Firstly the carotid arteries were collected 7 days after injury and quantitative realtime PCR was performed to analyze the inflammation level in vivo. The mRNA expression of 


\section{Cellular Physiology Cell Physiol Biochem 2015;37:719-734 \\ \begin{tabular}{l|l|l}
\hline DOI: 10.1159/000430390 2015 S. Karger AG, Basel &
\end{tabular} \\ and Biochemistry Published online: September 11, 2015 www.karger.com/cpb \\ Qi et al.: JMJD2A Inhibition Attenuates Neointimal Hyperplasia in Diabetic Rats}

MCP-1 and IL- 6 were up regulated after balloon injury compared with sham group. And this up-regulation was suppressed both in the 2, 4-PDCA group and siRNA-JMJD2A group (Fig. $6 \mathrm{~A}-\mathrm{B})$. Furthermore the protein expressions of inflammatory genes in vivo were detected using western blotting. As shown in Fig. 6C, MCP-1 and IL-6 were down regulated after the inhibition of JMJD2A. But the protein level of H3K9me3 in vivo showed an opposite trend (Fig. 6C). The reduced H3K9me3 was restored after the inhibition of JMJD2A. In addition, we performed immunohistochemical analysis to assess H3K9me3 expression in the neointima. Moderate H3K9me3 staining of the injured carotid arteries was initially observed both in saline and scrambled siRNA group (Fig. 6D-E), whereas H3K9me3 staining was elevated following the administration of 2,4-PDCA and the transfection of siRNA-JMJD2A. Thus the inhibition of JMJD2A restored H3K9me3 and suppressed the inflammatory response in injured arteries of diabetic rats.

\section{Discussion}

In this study we demonstrated that JMJD2A inhibition exerted protective effect against neointimal formation in diabetic rats following balloon injury through interfering with the high glucose induced proliferation and migration in VSMCs. Much evidence supports these findings: JMJD2A was increased in HG-treated VSMCs and balloon-injured arteries of diabetic rats, accompanied by the elevated proliferation, migration and inflammation in VSMCs; JMJD2A inhibition, by a chemical innibitor 2, 4-PDCA or siRNA, suppressed this HG-induced proliferation, migration and inflammation in vitro and attenuated neointimal formation in vivo. The underlying mechanism may be related to the elevated H3K9me3 occupancy at inflammatory genes promoters after JMJD2A inhibition, which transcriptionally inhibits inflammatory gene expression.

Diabetes is an independent risk factor for CAD [2]. Severe and diffuse lesions that progress rapidly characterize CAD in the setting of diabetes [35]. Diabetic individuals have lower long-term survival rates and higher rates of repeat revascularization $[6,7]$. Type 2 diabetes mellitus (T2DM) is a complicated metabolic disorder with hyperglycemia, hyperlipidemia, and hyperinsulinemia. The contribution of hyperglycemia on the neointima formation still remains controversial. Previous studies indicated that STZ-induced diabetes characterized by hyperglycemia and hypoinsulinemia cannot thicken neointima in response to arterial injury [36, 37]. However, Srivastava et al. proved that prolonging the exposure time of hyperglycemia resulted in neointimal hyperplasia, indicating that hyperglycemia can promote restenosis independent of hyperinsulinemia [24]. In vitro, high glucose triggers damage in varies kinds of cells [38-41]. In our study, we constructed T2DM rats model using 4-week HFD following low dose STZ injection that was approved as a convenient and economical method. Aggravated restenosis was observed in these HFD-STZ rats, which was consistent with Wang's study [42]. It is worth noting that the high glucose, rather than palmitate or insulin, promotes the expression of JMJD2A in vitro, indicating that JMJD2Amediated vascular remodeling in diabetes is more associated with hyperglycemia.

Recent studies have demonstrated that diabetic stimuli, especially high glucose, altered epigenetic chromatin markers at the promoters of pathogenic genes involved in the diabetic complications [43-45]. Histone methyltransferases Suv39H1 and SET7/9 facilitate the expression of NF- $\mathrm{KB}$ downstream of inflammatory genes via the methylation of $\mathrm{H} 3 \mathrm{~K} 9$ and H3K4 respectively $[19,46]$. And a reduced occupancy of demethylases LSD1 on the promoters of MCP-1 and IL- 6 is correlated with their increased expression in VSMCs under diabetic condition [47].

JMJD2A has been extensively studied, especially with regard to its role in cancer development [48]. It transcriptionally regulates cancer-related genes including cell cycle, proliferation and inflammation via either demethylation or interactions with N-CoR, pRB, histone deacetylases (HDACs) [49, 50]. We demonstrated that JMJD2A was increased in HGtreated VSMCs and balloon-injured carotid arteries of diabetic rats for the first time, which 


\section{Cellular Physiology Cell Physiol Biochem 2015;37:719-734 \\ \begin{tabular}{l|l} 
DOI: 10.1159/000430390 & \\
and Biochemistry Published online: September 11, 2015 & $\begin{array}{l}\text { O } 2015 \text { S. Karger AG, Basel } \\
\text { www.karger.com/cpb }\end{array}$
\end{tabular} \\ Qi et al.: JMJD2A Inhibition Attenuates Neointimal Hyperplasia in Diabetic Rats}

was accompanied with a reduced H3K9me3 at promoters of MCP-1 and IL-6. H3K9me3 plays an important role in gene repression and silencing [51]. Previous studies indicated that mesangial cells and endothelial cells cultured under HG conditions exhibited repressed $\mathrm{H} 3 \mathrm{~K} 9 \mathrm{me} 3$ that are correlated with increases in the expression of pathological genes [52]. We demonstrated the reduced H3K9me3 occupancy leads to the up regulated MCP-1 and IL-6 both in the mRNA and protein levels.

Neointimal hyperplasia following angioplasty was proposed to be similar to wound healing and divided into 3 phases: an inflammatory phase, a cellular proliferation phase, and an extracellular matrix remodeling phase [53]. The inflammation that contributes to deranged VSMC proliferation and migration plays a pivotal role in the physiological processes of restenosis [13]. IL-6 is a proinflammatory cytokine that promotes the secretion of multiple chemokines and up-regulates adhesion molecule expression. MCP-1 is an important factor in monocyte recruitment. They are important mediators of VSMC proliferation and migration $[54,55]$. In our study, the elevated expressions of MCP-1 and IL- 6 were accompanied with increased proliferation and migration both in vitro and in vivo. The neutralizing antibody against MCP-1 and IL-6 offset the HG-induced proliferation and migration informing that HG promoted proliferation and migration via the elevated inflammation. Our findings are consistent with previous studies signifying the role of inflammation in neointimal formation, especially under diabetic stimuli.

Given the potential effect of JMJD2A in diabetic complication, we executed JMJD2A inhibition by 2, 4-PDCA and siRNA. JMJD2A inhibition suppressed the proliferation and migration of VSMCs under diabetic stimuli through restoring $\mathrm{H} 3 \mathrm{~K} 9 \mathrm{me} 3$ at promoters of MCP-1 and IL- 6 and transcriptionally inhibiting these inflammatory genes. However the addition of recombinant MCP-1 or IL- 6 completely eliminated the inhibitory effect on HGstimulated proliferation and migration. Because JMJD2A is a potential therapeutic target in cancer, tremendous effort has been expended to design specific JMJD2 inhibitors [56]. 2, 4-PDCA exerts its inhibitory effects by not only competing with 20G but also occupying oxygen binding sites [57]. It has both immuno-suppressive and fibro-suppressive properties [58]. Previous studies have demonstrated that 2, 4-PDCA and platinum/ruthenium-based anticancer complexes exert modest antiproliferative and antimetastatic effects in tumor cells $[59,60]$. Mackeen et al. determined that 2, 4-PDCA derivatives inhibit JMJD2A in cells [61]. In our study, 2, 4-PDCA ameliorated neointimal formation in diabetic rats following balloon injury. However, it appears to be in disparate concentration-dependent manners in vivo or in vitro experiments. Actually we explored the potential influence of 2,4-PDCA on endothelial cells (EC) as well. Low-dose 2, 4-PDCA protected EC from high glucose more significantly (data not shown). Restenosis is a comprehensive result of neointimal formation and reendotheliazation.

\section{Conclusions}

In conclusion, we investigated the roles of JMJD2A and its substrate H3K9me3 in a hyper-inflammatory state involving VSMCs subjected to diabetic stimuli. Our findings established that JMJD2A inhibition attenuates neointimal hyperplasia in response to balloon injury in diabetes via the suppressed proliferation, migration and inflammation of VSMCs. And 2,4-PDCA may present as one promising option for the treatment of patients with CAD and diabetes.

\section{Acknowledgements}

This work was supported by National Natural Science Foundation of the People's Republic of China grants [81170195, 81200156]; and Fundamental Research Funds for the Central Universities [20120141120079]. We thank Tang Yanhong, Wang Xi, Wang Teng, Hu Ping from Renmin Hospital of Wuhan University for excellent technical assistance. 


\section{Cellular Physiology Cell Physiol Biochem 2015;37:719-734 \begin{tabular}{l|l|l|}
\hline DOI: 10.1159/000430390 & O 2015 S. Karger AG, Basel
\end{tabular} and Biochemistry Published online: September 11, 2015 www.karger.com/cpb

\section{Disclosure Statement}

None.

\section{References}

1 Teramoto T, Kawamori R, Miyazaki S, Teramukai S, Mori Y, Okuda Y, Hiramatsu K: Risk factors for primary prevention of cardiovascular disease and risk reduction by lipid control: The omega study risk factor subanalysis. Clin Exp Hypertens 2014;36:236-243.

2 Zimmet P, Alberti KG, Shaw J: Global and societal implications of the diabetes epidemic. Nature 2001;414:782-787.

3 Burke AP, Kolodgie FD, Zieske A, Fowler DR, Weber DK, Varghese PJ, Farb A, Virmani R: Morphologic findings of coronary atherosclerotic plaques in diabetics: A postmortem study. Arterioscler Thromb Vasc Biol 2004;24:1266-1271.

4 Virmani R, Burke AP, Kolodgie F: Morphological characteristics of coronary atherosclerosis in diabetes mellitus. Can J Cardiol 2006;22:81B-84B.

5 Minha S, Bental T, Assali A, Vaknin-Assa H, Lev EI, Rechavia E, Battler A, Kornowski R: A comparative analysis of major clinical outcomes using drug-eluting stents versus bare metal stents in diabetic versus nondiabetic patients. Catheter Cardiovasc Interv 2011;78:710-717.

6 Iijima R, Ndrepepa G, Mehilli J, Markwardt C, Bruskina O, Pache J, Ibrahim M, Schomig A, Kastrati A: Impact of diabetes mellitus on long-term outcomes in the drug-eluting stent era. Am Heart J 2007;154:688-693.

7 Jensen LO, Thayssen P, Junker A, Maeng M, Tilsted HH, Kaltoft A, Hansen KN, Christiansen EH, Kristensen SD, Ravkilde J, Madsen M, Sorensen HT, Thuesen L, Lassen JF: Comparison of outcomes in patients with versus without diabetes mellitus after revascularization with everolimus- and sirolimus-eluting stents (from the sort out iv trial). Am J Cardiol 2012;110:1585-1591.

8 Duckworth W, Abraira C, Moritz T, Reda D, Emanuele N, Reaven PD, Zieve FJ, Marks J, Davis SN, Hayward R, Warren SR, Goldman S, McCarren M, Vitek ME, Henderson WG, Huang GD: Glucose control and vascular complications in veterans with type 2 diabetes. N Engl J Med 2009;360:129-139.

9 Gerstein HC, Miller ME, Byington RP, Goff DC, Jr., Bigger JT, Buse JB, Cushman WC, Genuth S, Ismail-Beigi F, Grimm RH, Jr., Probstfield JL, Simons-Morton DG, Friedewald WT: Effects of intensive glucose lowering in type 2 diabetes. N Engl J Med 2008;358:2545-2559.

10 Patel A, MacMahon S, Chalmers J, Neal B, Billot L, Woodward M, Marre M, Cooper M, Glasziou P, Grobbee D, Hamet P, Harrap S, Heller S, Liu L, Mancia G, Mogensen CE, Pan C, Poulter N, Rodgers A, Williams B, Bompoint S, de Galan BE, Joshi R, Travert F: Intensive blood glucose control and vascular outcomes in patients with type 2 diabetes. N Engl J Med 2008;358:2560-2572.

11 Nathan DM, Cleary PA, Backlund JY, Genuth SM, Lachin JM, Orchard TJ, Raskin P, Zinman B: Intensive diabetes treatment and cardiovascular disease in patients with type 1 diabetes. $\mathrm{N}$ Engl J Med 2005;353:2643-2653.

12 Costa MA, Simon DI: Molecular basis of restenosis and drug-eluting stents. Circulation 2005;111:22572273.

13 Simon DI: Inflammation and vascular injury: Basic discovery to drug development. Circ J 2012;76:18111818.

14 Wegner M, Neddermann D, Piorunska-Stolzmann M, Jagodzinski PP: Role of epigenetic mechanisms in the development of chronic complications of diabetes. Diabetes Res Clin Pract 2014;105:164-175.

15 Bannister AJ, Kouzarides T: Reversing histone methylation. Nature 2005;436:1103-1106.

16 Martin C, Zhang Y: The diverse functions of histone lysine methylation. Nat Rev Mol Cell Biol 2005;6:838849.

17 Mosammaparast N, Shi Y: Reversal of histone methylation: Biochemical and molecular mechanisms of histone demethylases. Annu Rev Biochem 2010;79:155-179.

18 Shilatifard A: Chromatin modifications by methylation and ubiquitination: Implications in the regulation of gene expression. Annu Rev Biochem 2006;75:243-269.

19 Villeneuve LM, Reddy MA, Lanting LL, Wang M, Meng L, Natarajan R: Epigenetic histone h3 lysine 9 methylation in metabolic memory and inflammatory phenotype of vascular smooth muscle cells in diabetes. Proc Natl Acad Sci U S A 2008;105:9047-9052. 


\section{Cellular Physiology Cell Physiol Biochem 2015;37:719-734 \begin{tabular}{c|c|c|}
\cline { 2 - 2 } DOI: 10.1159/000430390 & (O) 2015 S. Karger AG, Basel \\
\hline
\end{tabular} and Biochemistry Published online: September 11, 2015 www.karger.com/cpb \\ Qi et al.: JMJD2A Inhibition Attenuates Neointimal Hyperplasia in Diabetic Rats}

20 Whetstine JR, Nottke A, Lan F, Huarte M, Smolikov S, Chen Z, Spooner E, Li E, Zhang G, Colaiacovo M, Shi Y: Reversal of histone lysine trimethylation by the jmjd2 family of histone demethylases. Cell 2006;125:467481.

21 Guerra-Calderas L, Gonzalez-Barrios R, Herrera LA, Cantu de Leon D, Soto-Reyes E: The role of the histone demethylase kdm4a in cancer. Cancer Genet 2015;208:215-224.

22 Wang L, Zheng J, Bai X, Liu B, Liu CJ, Xu Q, Zhu Y, Wang N, Kong W, Wang X: Adamts-7 mediates vascular smooth muscle cell migration and neointima formation in balloon-injured rat arteries. Circ Res 2009;104:688-698.

23 Chen J, Zhang J, Xu L, Xu C, Chen S, Yang J, Jiang H: Inhibition of neointimal hyperplasia in the rat carotid artery injury model by a hmgb1 inhibitor. Atherosclerosis 2012;224:332-339.

24 Srivastava S, Ramana KV, Tammali R, Srivastava SK, Bhatnagar A: Contribution of aldose reductase to diabetic hyperproliferation of vascular smooth muscle cells. Diabetes 2006;55:901-910.

25 Perdomo L, Beneit N, Otero YF, Escribano O, Diaz-Castroverde S, Gomez-Hernandez A, Benito M: Protective role of oleic acid against cardiovascular insulin resistance and in the early and late cellular atherosclerotic process. Cardiovasc Diabetol 2015;14:75.

26 Jiang H, Chen J, Wang L, Zhu LH, Wen HZ: Down-regulation of creb-binding protein expression inhibits thrombin-induced proliferation of endothelial cells: Possible relevance to pdgf-b. Cell Biol Int 2010;34:1155-1161.

27 Wu X, Wang J, Jiang H, Hu Q Chen J, Zhang J, Zhu R, Liu W, Li B: Wnt3a activates beta1-integrin and regulates migration and adhesion of vascular smooth muscle cells. Mol Med Rep 2014;9:1159-1164.

28 Xing D, Oparil S, Yu H, Gong K, Feng W, Black J, Chen YF, Nozell S: Estrogen modulates nfkappab signaling by enhancing ikappabalpha levels and blocking p65 binding at the promoters of inflammatory genes via estrogen receptor-beta. PLoS One 2012;7:e36890.

29 Uemura S, Matsushita H, Li W, Glassford AJ, Asagami T, Lee KH, Harrison DG, Tsao PS: Diabetes mellitus enhances vascular matrix metalloproteinase activity: Role of oxidative stress. Circ Res 2001;88:1291-1298.

30 Yang B, Yang J, Bai J, Pu P, Liu J, Wang F, Ruan B: Suv39h1 protects from myocardial ischemia-reperfusion injury in diabetic rats. Cell Physiol Biochem 2014;33:1176-1185.

31 Holt AW, Tulis DA: Experimental rat and mouse carotid artery surgery: Injury \& remodeling studies. ISRN Minim Invasive Surg 2013;2013

32 Yang J, Jiang H, Chen SS, Chen J, Li WQ, Xu SK, Wang JC: Lentivirus-mediated rnai targeting creb binding protein attenuates neointimal formation and promotes re-endothelialization in balloon injured rat carotid artery. Cell Physiol Biochem 2010;26:441-448.

33 Chen F, Xiong H, Wang J, Ding X, Shu G, Mei Z: Antidiabetic effect of total flavonoids from sanguis draxonis in type 2 diabetic rats. J Ethnopharmacol 2013;149:729-736.

34 Zhang J, Chen J, Yang J, Xu C, Ding J, Yang J, Guo Q, Hu Q, Jiang H: Sodium ferulate inhibits neointimal hyperplasia in rat balloon injury model. PLoS One 2014;9:e87561.

35 Canpolat U, Aytemir K, Yorgun H, Hazirolan T, Kaya EB, Ates AH, Sunman H, Dural M, Yalcin MU, Tokgozoglu L, Kabakci G, Oto A: Association of type 2 diabetes mellitus with coronary atherosclerotic plaque burden and morphology measured by multidetector computed tomography coronary angiography. Acta Cardiol 2012;67:71-77.

36 Park SH, Marso SP, Zhou Z, Foroudi F, Topol EJ, Lincoff AM: Neointimal hyperplasia after arterial injury is increased in a rat model of non-insulin-dependent diabetes mellitus. Circulation 2001;104:815-819.

37 Indolfi C, Torella D, Cavuto L, Davalli AM, Coppola C, Esposito G, Carriero MV, Rapacciuolo A, Di Lorenzo E, Stabile E, Perrino C, Chieffo A, Pardo F, Chiariello M: Effects of balloon injury on neointimal hyperplasia in streptozotocin-induced diabetes and in hyperinsulinemic nondiabetic pancreatic islet-transplanted rats. Circulation 2001;103:2980-2986.

38 Wang XM, Song SS, Xiao H, Gao P, Li XJ, Si LY: Fibroblast growth factor 21 protects against high glucose induced cellular damage and dysfunction of endothelial nitric-oxide synthase in endothelial cells. Cell Physiol Biochem 2014;34:658-671.

39 Chen F, Chen B, Xiao FQ, Wu YT, Wang RH, Sun ZW, Fu GS, Mou Y, Tao W, Hu XS, Hu SJ: Autophagy protects against senescence and apoptosis via the ras-mitochondria in high-glucose-induced endothelial cells. Cell Physiol Biochem 2014;33:1058-1074.

40 Castiglione RC, Maron-Gutierrez T, Barbosa CM, Ornellas FM, Barreira AL, Dibarros CB, Vasconcelos-dosSantos A, Paredes BD, Pascarelli BM, Diaz BL, Rossi-Bergmann B, Takiya CM, Rocco PR, Souza-Menezes J, Morales MM: Bone marrow-derived mononuclear cells promote improvement in glomerular function in 


\section{Cellular Physiology Cell Physiol Biochem 2015;37:719-734 \begin{tabular}{ll|l} 
and Biochemistry & $\begin{array}{l}\text { DOI: 10.1159/000430390 } \\
\text { Published online: September 11, } 2015\end{array}$ & $\begin{array}{l}\text { C } 2015 \text { S. Karger AG, Basel } \\
\text { www.karger.com/cpb }\end{array}$ \\
\hline
\end{tabular} \\ Qi et al.: JMJD2A Inhibition Attenuates Neointimal Hyperplasia in Diabetic Rats}

rats with early diabetic nephropathy. Cell Physiol Biochem 2013;32:699-718.

41 Carrillo-Sepulveda MA, Matsumoto T: Phenotypic modulation of mesenteric vascular smooth muscle cells from type 2 diabetic rats is associated with decreased caveolin-1 expression. Cell Physiol Biochem 2014;34:1497-1506.

42 Wang K, Wen L, Peng W, Li H, Zhuang J, Lu Y, Liu B, Li X, Li W, Xu Y: Vinpocetine attenuates neointimal hyperplasia in diabetic rat carotid arteries after balloon injury. PLoS One 2014;9:e96894.

43 Smith E, Shilatifard A: The chromatin signaling pathway: Diverse mechanisms of recruitment of histonemodifying enzymes and varied biological outcomes. Mol Cell 2010;40:689-701.

44 El-Osta A, Brasacchio D, Yao D, Pocai A, Jones PL, Roeder RG, Cooper ME, Brownlee M: Transient high glucose causes persistent epigenetic changes and altered gene expression during subsequent normoglycemia. J Exp Med 2008;205:2409-2417.

45 Brasacchio D, Okabe J, Tikellis C, Balcerczyk A, George P, Baker EK, Calkin AC, Brownlee M, Cooper ME, El-Osta A: Hyperglycemia induces a dynamic cooperativity of histone methylase and demethylase enzymes associated with gene-activating epigenetic marks that coexist on the lysine tail. Diabetes 2009;58:12291236.

46 Li Y, Reddy MA, Miao F, Shanmugam N, Yee JK, Hawkins D, Ren B, Natarajan R: Role of the histone h3 lysine 4 methyltransferase, set7/9, in the regulation of nf-kappab-dependent inflammatory genes. Relevance to diabetes and inflammation. J Biol Chem 2008;283:26771-26781.

47 Mishra M, Zhong Q Kowluru RA: Epigenetic modifications of nrf2-mediated glutamate-cysteine ligase: Implications for the development of diabetic retinopathy and the metabolic memory phenomenon associated with its continued progression. Free Radic Biol Med 2014;75:129-139.

48 Berry WL, Janknecht R: Kdm4/jmjd2 histone demethylases: Epigenetic regulators in cancer cells. Cancer Res 2013;73:2936-2942.

49 Kogure M, Takawa M, Cho HS, Toyokawa G, Hayashi K, Tsunoda T, Kobayashi T, Daigo Y, Sugiyama M, Atomi Y, Nakamura Y, Hamamoto R: Deregulation of the histone demethylase jmjd2a is involved in human carcinogenesis through regulation of the g(1)/s transition. Cancer Lett 2013;336:76-84.

50 Das A, Chai JC, Jung KH, Das ND, Kang SC, Lee YS, Seo H, Chai YG: Jmjd2a attenuation affects cell cycle and tumourigenic inflammatory gene regulation in lipopolysaccharide stimulated neuroectodermal stem cells. Exp Cell Res 2014;328:361-378.

51 Lachner M, O'Carroll D, Rea S, Mechtler K, Jenuwein T: Methylation of histone h3 lysine 9 creates a binding site for hp1 proteins. Nature 2001;410:116-120.

52 Sun G, Reddy MA, Yuan H, Lanting L, Kato M, Natarajan R: Epigenetic histone methylation modulates fibrotic gene expression. J Am Soc Nephrol 2010;21:2069-2080.

53 Forrester JS, Fishbein M, Helfant R, Fagin J: A paradigm for restenosis based on cell biology: Clues for the development of new preventive therapies. J Am Coll Cardiol 1991;17:758-769.

54 Nabata T, Morimoto S, Koh E, Shiraishi T, Ogihara T: Interleukin-6 stimulates c-myc expression and proliferation of cultured vascular smooth muscle cells. Biochem Int 1990;20:445-453.

55 Wang Z, Newman WH: Smooth muscle cell migration stimulated by interleukin 6 is associated with cytoskeletal reorganization. J Surg Res 2003;111:261-266.

56 Lohse B, Kristensen JL, Kristensen LH, Agger K, Helin K, Gajhede M, Clausen RP: Inhibitors of histone demethylases. Bioorg Med Chem 2011;19:3625-3636.

57 Chang KH, King ON, Tumber A, Woon EC, Heightman TD, McDonough MA, Schofield CJ, Rose NR: Inhibition of histone demethylases by 4-carboxy-2,2'-bipyridyl compounds. ChemMedChem 2011;6:759-764.

58 Sharir M, Zimmerman TJ: In vitro inhibition of collagen formation by 2,4-pyridine dicarboxylate and minoxidil in rabbit corneal fibroblasts. Curr Eye Res 1993;12:553-559.

59 Rakic GM, Grguric-Sipka S, Kaluderovic GN, Bette M, Filipovic L, Arandelovic S, Radulovic S, Tesic Z: The synthesis, spectroscopic, x-ray characterization and in vitro cytotoxic testing results of activity of five new trans-platinum(iv) complexes with functionalized pyridines. Eur J Med Chem 2012;55:214-219.

60 Gligorijevic N, Arandelovic S, Filipovic L, Jakovljevic K, Jankovic R, Grguric-Sipka S, Ivanovic I, Radulovic $\mathrm{S}$, Tesic Z: Picolinate ruthenium(ii)-arene complex with in vitro antiproliferative and antimetastatic properties: Comparison to a series of ruthenium(ii)-arene complexes with similar structure. J Inorg Biochem 2012;108:53-61.

61 Mackeen MM, Kramer HB, Chang KH, Coleman ML, Hopkinson RJ, Schofield CJ, Kessler BM: Small-moleculebased inhibition of histone demethylation in cells assessed by quantitative mass spectrometry. J Proteome Res 2010;9:4082-4092. 